\title{
Low-dose Dexamethasone in the Prevention of Postoperative Nausea and Vomiting After Total Joint Arthroplasty: a Retrospective Study
}

Quan Mao ( $\square$ maoquanhz@163.com )

Hangzhou Fuchun Traditional Chinese Medicine Orthopaedic Hospital

\section{Yongcheng Wu}

Hangzhou Fuchun Traditional Chinese Medicine Orthopaedic Hospital

\section{Bin Chen}

Hangzhou Fuchun Traditional Chinese Medicine Orthopaedic Hospital

\section{Research Article}

Keywords: dexamethasone, 5 mg, vomiting, nausea, arthroplasty

Posted Date: October 26th, 2021

DOI: https://doi.org/10.21203/rs.3.rs-953261/v1

License: (a) This work is licensed under a Creative Commons Attribution 4.0 International License. Read Full License 


\section{Abstract}

Background To investigate the clinical efficacy and safety of prophylactic low-dose dexamethasone for postoperative nausea and vomiting (PONV) after total joint arthroplasty.

Methods a total of 100 patients who underwent primary total knee or hip arthroplasty were enrolled. Patients were divided into placebo group (received $1 \mathrm{ml}$ normal saline), and Dexa group (received $5 \mathrm{mg}$ dexamethasone). The incidence of PONV was recorded and divided into 4 levels for statistical comparison. The occurrences of postoperative complications, the numerical rating scales for pain, the consumption of analgesic and antiemetic rescue, and the patient satisfaction rate were counted and compared.

Results In the Dexa group, patients had a lower incidence of level $₫$ or higher PONV than those in the placebo group ( $p<0.05)$, as well as the amount of additional antiemetic drugs. The pain level and consumption of analgesics were similar in the two groups. No delayed wound healing or gastrointestinal hemorrhage was observed in either group. One patient in the placebo group got early surgical site infection occurred with no statistical significance. Patients in Dexa group had a higher subjective satisfaction rate.

Conclusion The prophylactic application of $5 \mathrm{mg}$ dexamethasone during induction of anesthesia can effectively reduce the incidence of severe PONV after the initial total joint replacement and the consumption of antiemetic drugs, improve the patient's care experience, and will not bring significant clinical harm.

\section{Background}

Total joint arthroplasty (TJA) is currently the most effective treatment for end-stage joint diseases, such as osteoarthritis and rheumatoid arthritis[1]. The demand for artificial joint replacement is rising sharply, over 1 million joint arthroplasties are performed annually in the United States [2]. Postoperative nausea and vomiting (PONV) are one of the most common complications. Although surgical and anesthesia techniques have matured in recent years, there are still $20-30 \%$ of patients will experience PONV reactions[3-5]. PONV is an important cause of dissatisfaction among postoperative patients [6,7]. Although PONV can recover on its own, if it is not controlled in time, it may lead to incision dehiscence, infection, and aspiration pneumonia, which will seriously affect postoperative recovery[8].

So far, the drugs with high-quality evidence that have a clear effect on preventing the PONV include aprepitant, ramosetron, granisetron, dexamethasone, and ondansetron. These drugs have been proven to be effective regardless of whether they are used alone or in combination [9]. Among them, dexamethasone can reduce pain while antiemetic, seems to be more suitable for orthopedic surgery, which will cause severe pain when recovering functional after operation [10-12].In 2020, the American Society of Enhanced Recovery and Society for Ambulatory Anesthesia has proposed the guideline stating that when used as a single drug to prevent PONV, the recommended dosage of dexamethasone is 4 8 $\mathrm{mg}[13]$. However, this recommended dose is based on the results of multiple types of surgical procedures, and more from laparoscopic surgery researches. Previously, almost all orthopedic studies focused on doses of $10 \mathrm{mg}$ or above. In addition, many studies have raised safety issues related to dexamethasone, such as increased postoperative blood glucose and potential immunosuppressive effects, and these side effects are in a dose-manner [13-15]. 
Based on the above, we reviewed the patients who underwent TJA surgery in our hospital in the past 2 years to evaluate the clinical efficacy of $5 \mathrm{mg}$ dexamethasone on preventing PONV. We are expected to reveal: (1) whether the lowest dose of dexamethasone recommended by the clinical guideline is effective in inhibiting the occurrence of PONV in TJA surgery; (2) whether there are potential risks with 5 mg dexamethasone; (3) whether $5 \mathrm{mg}$ dexamethasone shows an advantage in various indicators.

\section{Methods}

\section{Patients}

The inclusion criteria were as follows: $₫$ received primary hip or knee replacement due to osteoarthritis; $₫ A S A$

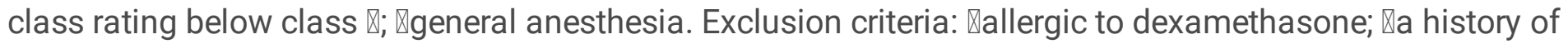
high-dose glucocorticoid use; $\Downarrow$ combined with other diseases that require glucocorticoid therapy, such as systemic lupus erythematosus; 『combined with other diseases that were inappropriate to use glucocorticoids, such as a peptic ulcer.

According to the above criteria, 100 patients who received TJA in our hospital due to osteoarthritis between April 2018 and December 2020 were enrolled, including 39 males and 61 females. 50 each in the placebo group and Dexa group. The diagnosis of osteoarthritis in all patients meets the diagnostic criteria of the American college of rheumatology (ACR) [16].

\section{Surgical procedure}

All arthroplasties were performed by the same experienced surgeon. All patients underwent general anesthesia with tracheal intubation, and $1.5 \mathrm{~g}$ cefuroxime sodium was given intravenously 30 minutes before the operation for infection prophylaxis. Dexamethasone (1 ml: 5 mg, Tianjin Kingyork group co., Itd., China) was injected intravenously by an anesthesiologist during induction of anesthesia. The placebo group received $1 \mathrm{ml}$ saline. A midline skin incision, the medial parapatellar approach was applied in total knee arthroplasty. An intramedullary alignment system was used for femoral preparation, and an extramedullary alignment system was used for tibial preparation. For patients who received hip arthroplasty surgery, a small incision was made in the skin along the posterior thigh and incised through the gluteus medius to expose the joint cavity. Choose the most suitable prosthesis according to the specific situation of the patients.

\section{Postoperative management}

Postoperative managements of all patients meet the same scheme. After the operation, cefuroxime sodium was used to prevent infection, twice a day, $1.5 \mathrm{~g}$ each time, for 3 consecutive days. One tablet Xarelto was administered daily to prevent deep vein thrombosis. Flurbiprofen axetil injection was used routinely twice a day (50 mg each time) for preemptive analgesia. If the NRS score was greater than 4, use dezocine ( $1 \mathrm{ml}$ : $5 \mathrm{mg}$, Yangzijiang pharmaceutical group co., Itd.) as an analgesic rescue. When a grade $\otimes$ PONV reaction occurred, or the patient required antiemetic drugs, the first-line rescue was metoclopramide (1ml: $10 \mathrm{mg}$, Tianjin Kingyork group co., Itd., China). An intramuscular injection of ondansetron (2ml: 4mg, Qilu Hainan pharmaceutical group co., Itd.) would be used if PONV was not relieved within 30 45 minutes. 
The daily functional exercise started the next day after surgery. Intermittent inflation treatment in lower limb for about 30 minutes every morning to prevent deep venous thrombosis. Under the guidance of a professional physiotherapist, all patients adhered to quadriceps exercise and extension-flexion training, and strictly implemented phased muscle strength training to ensure that they can walk within 24 hours if all went well.

\section{Outcome recording}

The primary outcomes were PONV level and the amount of rescue drug consumption. The severity of PONV

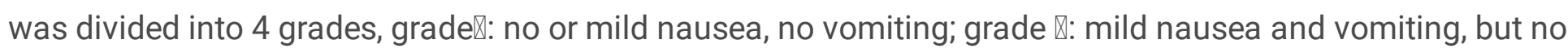

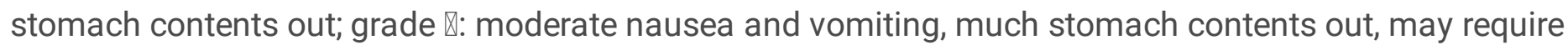

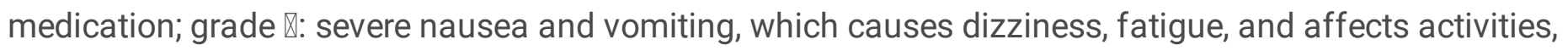
must be controlled by medication.

The secondary outcomes were the following: (1) pain level and the amount of dezocine consumption, (2) length of hospital stay (LOS), (3) postoperative complications, (4) patient satisfaction. The pain level was assessed by the numerical rating scales (NRS, 0-10, 0 means no pain, 10 means severe pain). All patients were followed up for at least 3 months after discharge to record whether there were any complications such as surgical site infection, delayed wound healing, and gastrointestinal bleeding. Patient satisfaction was obtained through a questionnaire.

\section{Statistical analysis}

All data analyses were performed by SPSS version 23 (SPSS inc., Chicago, IL, USA). Mean values and standard deviations were calculated for continuous variables. Student's t-test or Wilcoxon-Mann-Whitney u test was used to analyze quantitative data. Pearson chi-squared test or fisher's exact test was used to compare categorical data. Statistically significant was defined as $p<0.05$.

\section{Results}

\section{Patient baseline demographics}

The preoperative baseline data of the two groups of patients included age, sex, body mass index, ASA class, combined with diabetes and surgical time. We found no statistical difference between the two groups (Table 1). 
Table 1

Characteristics of the patients

\begin{tabular}{|c|c|c|c|c|c|c|c|c|c|}
\hline \multirow[t]{2}{*}{ Group } & \multirow[t]{2}{*}{ Cases } & \multirow[t]{2}{*}{ Age (y) } & \multicolumn{2}{|l|}{ Sex } & \multirow{2}{*}{$\begin{array}{l}\text { BMI } \\
\left(\mathrm{kg} / \mathrm{m}^{2}\right)\end{array}$} & \multicolumn{2}{|c|}{$\begin{array}{l}\text { ASA } \\
\text { class }\end{array}$} & \multirow{2}{*}{$\begin{array}{l}\text { Combined } \\
\text { with } \\
\text { diabetes }\end{array}$} & \multirow[t]{2}{*}{$\begin{array}{l}\text { Surgical } \\
\text { time (min) }\end{array}$} \\
\hline & & & Male & Female & & $\square$ & प & & \\
\hline $\begin{array}{l}\text { Placebo } \\
\text { group }\end{array}$ & 50 & $64.2 \pm 9.4$ & 18 & 32 & $23.93 \pm 3.48$ & 19 & 31 & 8 & $85.88 \pm 25.50$ \\
\hline $\begin{array}{l}\text { Dexa } \\
\text { group }\end{array}$ & 50 & $63.6 \pm 8.2$ & 21 & 29 & $23.80 \pm 3.13$ & 25 & 25 & 3 & $80.59 \pm 21.79$ \\
\hline $\mathrm{Pl}$ & - & 0.572 & 0.539 & & 0.753 & 0.2 & & 0.110 & 0.824 \\
\hline
\end{tabular}

\section{PONV and drug rescue}

There was no significant difference in the overall incidence of PONV between the two groups $(p=0.313)$. But a subgroup analysis of PONV of different severity revealed that the incidence of PONV above grade $\triangle$ in the Dexa group was significantly lower $(p=0.038)$. At the same time, patients in the Dexa group received a lower amount of metoclopramide and ondansetron, which was statistically significant compared to the placebo group ( $p=0.015, p<0.001$, respectively) (Table 2 ).

Table 2

PONV and drug rescue

\begin{tabular}{|c|c|c|c|c|c|c|c|c|}
\hline \multirow[t]{2}{*}{ Group } & \multicolumn{6}{|c|}{ PONV } & \multirow{2}{*}{$\begin{array}{l}\text { Metoclopramide } \\
\text { (mg) }\end{array}$} & \multirow{2}{*}{$\begin{array}{l}\text { Ondansetron } \\
\text { (mg) }\end{array}$} \\
\hline & प & $\square$ & 口 & प & $\nabla+\square$ & $\bigotimes+\bigotimes+\square$ & & \\
\hline Placebo group & 26 & 12 & 8 & 4 & 12 & 24 & $4.60 \pm 5.79$ & $1.60 \pm 2.80$ \\
\hline Dexa group & 31 & 15 & 3 & 1 & 4 & 19 & $2.80 \pm 4.96$ & $0.32 \pm 1.36$ \\
\hline$P$-value & - & 0.920 & 0.100 & 0.140 & 0.038 & 0.313 & 0.015 & $<0.001$ \\
\hline
\end{tabular}

\section{Pain and drug rescue}

NRS in the Dexa group was significantly lower than that of the other one at $24 \mathrm{~h}$ after operation $(P=0.018)$. The pain in both groups was similar at $48 \mathrm{~h}$ or $72 \mathrm{~h}$ after the operation (Fig. 1). We did not find a significant difference in dezocine consumption between the two groups (Table 3). 
Table 3

Pain and drug rescue

\begin{tabular}{|c|c|c|c|c|c|}
\hline \multirow[t]{2}{*}{ Group } & \multicolumn{4}{|l|}{ NRS } & \multirow{2}{*}{$\begin{array}{l}\text { Dezocine } \\
\text { (mg) }\end{array}$} \\
\hline & Pre & $24 \mathrm{~h}$ & $48 \mathrm{~h}$ & $72 \mathrm{~h}$ & \\
\hline Placebo group & $3.2 \pm 1.4$ & $2.9 \pm 1.1$ & $2.2 \pm 0.8$ & $1.9 \pm 0.8$ & $5.20 \pm 4.28$ \\
\hline Dexa group & $2.8 \pm 0.5$ & $2.0 \pm 0.9$ & $2.1 \pm 0.8$ & $1.8 \pm 0.8$ & $2.60 \pm 2.90$ \\
\hline$P$-value & - & 0.018 & 0.665 & 0.303 & 0.161 \\
\hline
\end{tabular}

\section{LOS, complications, and patient satisfaction}

There was no significant difference in the incidence of postoperative complications between the two groups. One person in the placebo group had a superficial infection of the incision after surgery, which presented with local redness and elevated skin temperature. After daily dressing changes and oral antibiotics for 3 weeks, the incision healed normally. No other complications were found, including delayed incision healing and gastrointestinal bleeding. The questionnaire results showed that the patients' satisfaction in the Dexa group was higher and statistically significant (Table 4).

Table 4

Postoperative Outcomes.

\begin{tabular}{|llllllll|}
\hline Group & LOS (day) & \multicolumn{2}{l}{ Complications } & & \multicolumn{2}{l|}{$\begin{array}{l}\text { Satisfaction } \\
\text { rate }\end{array}$} \\
\cline { 3 - 7 } & & Infection & $\begin{array}{l}\text { Delayed } \\
\text { healing }\end{array}$ & $\begin{array}{l}\text { Gastrointestinal } \\
\text { bleeding }\end{array}$ & Yes & No \\
\hline $\begin{array}{l}\text { Placebo } \\
\text { group }\end{array}$ & $8.72 \pm 3.74$ & $1 / 50$ & 0 & 0 & $43 / 50$ & $7 / 50$ \\
\hline Dexa group & $8.25 \pm 1.92$ & 0 & 0 & 0 & $49 / 50$ & $1 / 50$ \\
\hline$P$-value & 0.480 & 1.000 & - & - & 0.027 & \\
\hline
\end{tabular}

\section{Discussion}

In this retrospective study, for the first time, we prove that a single dose of $5 \mathrm{mg}$ intravenous dexamethasone at induction significantly reduces the incidence of severe PONV and the consumption of antiemetic drugs. We find non-significant short-term hazardousness despite no significance in terms of reducing the overall incidence of PONV and analgesia either.

The antiemetic mechanism of dexamethasone may be multifaceted. Dexamethasone has a significant antiinflammatory effect, which is helpful to reduce gastrointestinal irritation. Secondly, it can also directly suppress the brain stem emetic center. Furthermore, dexamethasone can reduce pain, which can reduce the dosage of opioids to prevent related drug-induced vomiting [17]. 
Previous studies suggested that the dose of dexamethasone used for adult antiemetics should be above 8 $\mathrm{mg}$ [11], Therefore, most studies have focused on doses of $8 \mathrm{mg}$ and above. Klag et al. [18]found that patients who received $10 \mathrm{mg}$ of dexamethasone showed lower consumption of ondansetron and morphine when there was no difference in the incidence of PONV during shoulder arthroplasty. Dissanayake et al. [19] used 2 injections of $8 \mathrm{mg}$ dexamethasone on 86 total hip replacement patients and found that the dose of antiemetic drugs in the study group decreased by $40 \%$, and the dose of morphine decreased by $27 \%$. Backes et al.[20] proved that the combined administration of $10 \mathrm{mg}$ dexamethasone and other antiemetic drugs can enhance the antiemetic effect in patients undergoing unilateral total hip or knee replacement. However, there is increasing evidence that lower dose of dexamethasone may also exert antiemetic effects [21, 22]. The fourth consensus guidelines for the management of postoperative nausea and vomiting suggested that the recommended dose of dexamethasone range between 4 and $10 \mathrm{mg}$ [13]. Our study verifies the clinical effect of the lowest dose in TJA surgery and prove that it can significantly reduce the occurrence of severe PONV and the number of antiemetic drugs after surgery.

Although it is generally believed that the safety of dexamethasone in perioperative treatment is dependable, there are still uncertainties. Studies have pointed out that dexamethasone could cause headache, dizziness, vertigo, chest pain, and other adverse reactions in patients after surgery[23]. Orthopedic physicians are more concerned about another side effect of dexamethasone, the blood glucose fluctuations. It has been proved that the effect on postoperative blood glucose fluctuations of dexamethasone mainly occurs within 24 hours after surgery, causing the potential risk of wound complications [24, 25]. However, Richardson et al. [26] retrospectively analyzed 6294 patients and found that receiving $4-10 \mathrm{mg}$ of dexamethasone during the perioperative period as an antiemetic and analgesic drug in joint replacement did not increase the postoperative infection. In this study, the patients have been followed up for 3 months, and no wound infection or delayed wound healing is observed in the Dexa group. The results support that $5 \mathrm{mg}$ dexamethasone is reliable and safe in TJA surgery.

The study find that the $5 \mathrm{mg}$ dexamethasone analgesic effect is limited. The NRS score at 24 hours after surgery showed a statistically significant decrease, but it did not have practical clinical implications. At the same time, it is not helpful to reduce the amount of pain medications. However, it helps improve the quality of patient experience, which is reflected in the increase in subjective satisfaction.

There are some limitations. This study explored the relationship between dosage and clinical effects but did not study whether different timing of administration, multiple administrations, and a combination with other drugs will affect the effect. In addition, limited by the study design, we were unable to obtain clinical data of $10 \mathrm{mg}$ or $20 \mathrm{mg}$, which were more commonly used in other studies, to analyze whether there is a difference between these doses. This study has only 3-month follow-up results which can rule out acute complications, but the long-term effects of dexamethasone after TJA surgery cannot be studied. Further investigations are needed.

\section{Conclusions}

Briefly, this study is the first to find that $5 \mathrm{mg}$ dexamethasone can effectively reduce the incidence of severe PONV and the consumption of antiemetic drugs in total joint arthroplasty, improve the patient's care 
experience, and bring no significant difference in short-term complications.

\section{Abbreviations}

TJA: Total joint arthroplasty; PONV: Postoperative nausea and vomiting; NRS: numerical rating scales

\section{Declarations}

\section{Ethics approval and consent to participate}

This retrospective study was approved by the Ethics Committee of Hangzhou Fuchun Traditional Chinese Medicine Orthopaedic Hospital (2021-KL-073-01) and obtained a waiver of informed consent. All methods were performed in accordance with the relevant guidelines and regulations, see:

https://www.biomedcentral.com/getpublished/editorial-policies\#ethics+and+consent.

\section{Consent for publication}

Not applicable

\section{Availability of data and materials}

The datasets used and/or analyzed during the current study are available from the corresponding author on reasonable request.

\section{Competing interests}

All authors declare that they have no competing interests.

\section{Funding}

Not applicable

\section{Authors' contributions}

QM, YW, and BC conceived of the study, participated in its design and coordination and helped to draft the manuscript. QM carried out the design of the study and complete the follow-up, and he was the principal coordinator of all aspects of this research. YW and BC carried out the editing of the text and graphics and the statistical analysis. BC was responsible for the translation into English and prepared the edition of this manuscript for publication. All authors read and approved the final manuscript.

\section{Acknowledgements}

Not applicable

\section{References}


1. Andersen LO, Gaarn-Larsen L, Kristensen BB, Husted H, Otte KS, Kehlet H: Subacute pain and function after fast-track hip and knee arthroplasty. Anaesthesia 2009, 64(5):508-513.

2. Hilibrand AS, Rubin LE, Grauer JN: Geographic Variations and Trends in Primary and Revision Knee and Total Hip Arthroplasties in the United States. JB JS Open Access 2020, 5(2):e0051.

3. Wasko MK, Bobecka-Wesolowska K, Tomasiuk R, Kowalczewski J: Measurement of the inflammatory response in the early postoperative period after hip and knee arthroplasty. Clin Chem Lab Med 2015, 53(11):1785-1792.

4. Aasvang EK, Luna IE, Kehlet $\mathrm{H}$ : Challenges in postdischarge function and recovery: the case of fast-track hip and knee arthroplasty. Br J Anaesth 2015, 115(6):861-866.

5. Cao G, Huang Q, Huang Z, Zhang S, Luo Z, Lei Y, Zhou Z, Pei F: The efficacy and safety of multiple-dose oral tranexamic acid on blood loss following total hip arthroplasty: a randomized controlled trial. Int Orthop 2019, 43(2):299-305.

6. Myles PS, Williams DL, Hendrata M, Anderson H, Weeks AM: Patient satisfaction after anaesthesia and surgery: results of a prospective survey of 10,811 patients. $B r J$ Anaesth 2000, 84(1):6-10.

7. Gan T, Sloan F Fau - Dear GdL, Dear Gde L Fau - El-Moalem HE, El-Moalem He Fau - Lubarsky DA, Lubarsky DA: How much are patients willing to pay to avoid postoperative nausea and vomiting? (00032999 (Print)).

8. Myklejord DJ, Yao L, Liang H, Glurich I: Consensus guideline adoption for managing postoperative nausea and vomiting. WMJ 2012, 111(5):207-213; quiz 214.

9. Weibel S, Schaefer MS, Raj D, Rucker G, Pace NL, Schlesinger T, Meybohm P, Kienbaum P, Eberhart LHJ, Kranke P: Drugs for preventing postoperative nausea and vomiting in adults after general anaesthesia: an abridged Cochrane network meta-analysis. Anaesthesia 2021, 76(7):962-973.

10. Lunn TH, Kehlet H: Perioperative glucocorticoids in hip and knee surgery - benefit vs. harm? A review of randomized clinical trials. Acta Anaesthesiol Scand 2013, 57(7):823-834.

11. Fujii $Y$, Nakayama M: Effects of dexamethasone in preventing postoperative emetic symptoms after total knee replacement surgery: a prospective, randomized, double-blind, vehicle-controlled trial in adult Japanese patients. Clin Ther 2005, 27(6):740-745.

12. Singh PM, Borle A, Panwar R, Makkar JK, McGrath I, Trikha A, Sinha A: Perioperative antiemetic efficacy of dexamethasone versus 5-HT3 receptor antagonists: a meta-analysis and trial sequential analysis of randomized controlled trials. Eur J Clin Pharmacol 2018, 74(10):1201-1214.

13. Gan TJ, Belani KG, Bergese S, Chung F, Diemunsch P, Habib AS, Jin Z, Kovac AL, Meyer TA, Urman RD et al: Fourth Consensus Guidelines for the Management of Postoperative Nausea and Vomiting. Anesth Analg 2020, 131(2):411-448.

14. Meng J, Li L: The efficiency and safety of dexamethasone for pain control in total joint arthroplasty: A meta-analysis of randomized controlled trials. Medicine (Baltimore) 2017, 96(24):e7126.

15. Wiesmann T, Kranke P, Eberhart L: Postoperative nausea and vomiting - a narrative review of pathophysiology, pharmacotherapy and clinical management strategies. Expert Opin Pharmacother 2015, 16(7):1069-1077.

16. Altman RD: Classification of disease: osteoarthritis. Semin Arthritis Rheum 1991, 20(6 Suppl 2):40-47. 
17. Moore SG: Intravenous Dexamethasone as an Analgesic: A Literature Review. (2162-5239 (Electronic)).

18. Klag EA, Kuhlmann NA, Tramer JS, Franovic S, Muh SJ: Dexamethasone decreases postoperative opioid and antiemetic use in shoulder arthroplasty patients: a prospective, randomized controlled trial. $J$ Shoulder Elbow Surg 2021, 30(7):1544-1552.

19. Dissanayake R, Du HN, Robertson IK, Ogden K, Wiltshire K, Mulford JS: Does Dexamethasone Reduce Hospital Readiness for Discharge, Pain, Nausea, and Early Patient Satisfaction in Hip and Knee Arthroplasty? A Randomized, Controlled Trial. J Arthroplasty 2018, 33(11):3429-3436.

20. Backes JR, Bentley JC, Politi JR, Chambers BT: Dexamethasone reduces length of hospitalization and improves postoperative pain and nausea after total joint arthroplasty: a prospective, randomized controlled trial. J Arthroplasty 2013, 28(8 Suppl):11-17.

21. De Oliveira GS, Jr., Castro-Alves LJ, Ahmad S, Kendall MC, McCarthy RJ: Dexamethasone to prevent postoperative nausea and vomiting: an updated meta-analysis of randomized controlled trials. Anesth Analg 2013, 116(1):58-74.

22. Gupta R, Srivastava S, Dhiraaj S, Chovatiya PP: Minimum Effective dose of Dexamethasone in Combination with Midazolam as Prophylaxis against Postoperative Nausea and Vomiting after Laparoscopic Cholecystectomy. Anesthesia, essays and researches 2018, 12(2):396-401.

23. Mackenzie J: Guidelines and use of dexamethasone for postoperative nausea and vomiting. Anaesthesia 2013, 68(12):1285-1286.

24. Pasternak JJ, McGregor DG, Lanier WL: Effect of singledose dexamethasone on blood glucose concentration in patients undergoing craniotomy. Journal of neurosurgical anesthesiology 2004, 16(2):122-125.

25. Polderman JA, Farhang-Razi V, Van Dieren S, Kranke P, DeVries JH, Hollmann MW, Preckel B, Hermanides $\mathrm{J}$ : Adverse side effects of dexamethasone in surgical patients. The Cochrane database of systematic reviews 2018, 11(11):Cd011940.

26. Richardson AB, Bala A, Wellman SS, Attarian DE, Bolognesi MP, Grant SA: Perioperative Dexamethasone Administration Does Not Increase the Incidence of Postoperative Infection in Total Hip and Knee Arthroplasty: A Retrospective Analysis. J Arthroplasty 2016, 31(8):1784-1787.

\section{Figures}




\section{Pain level}

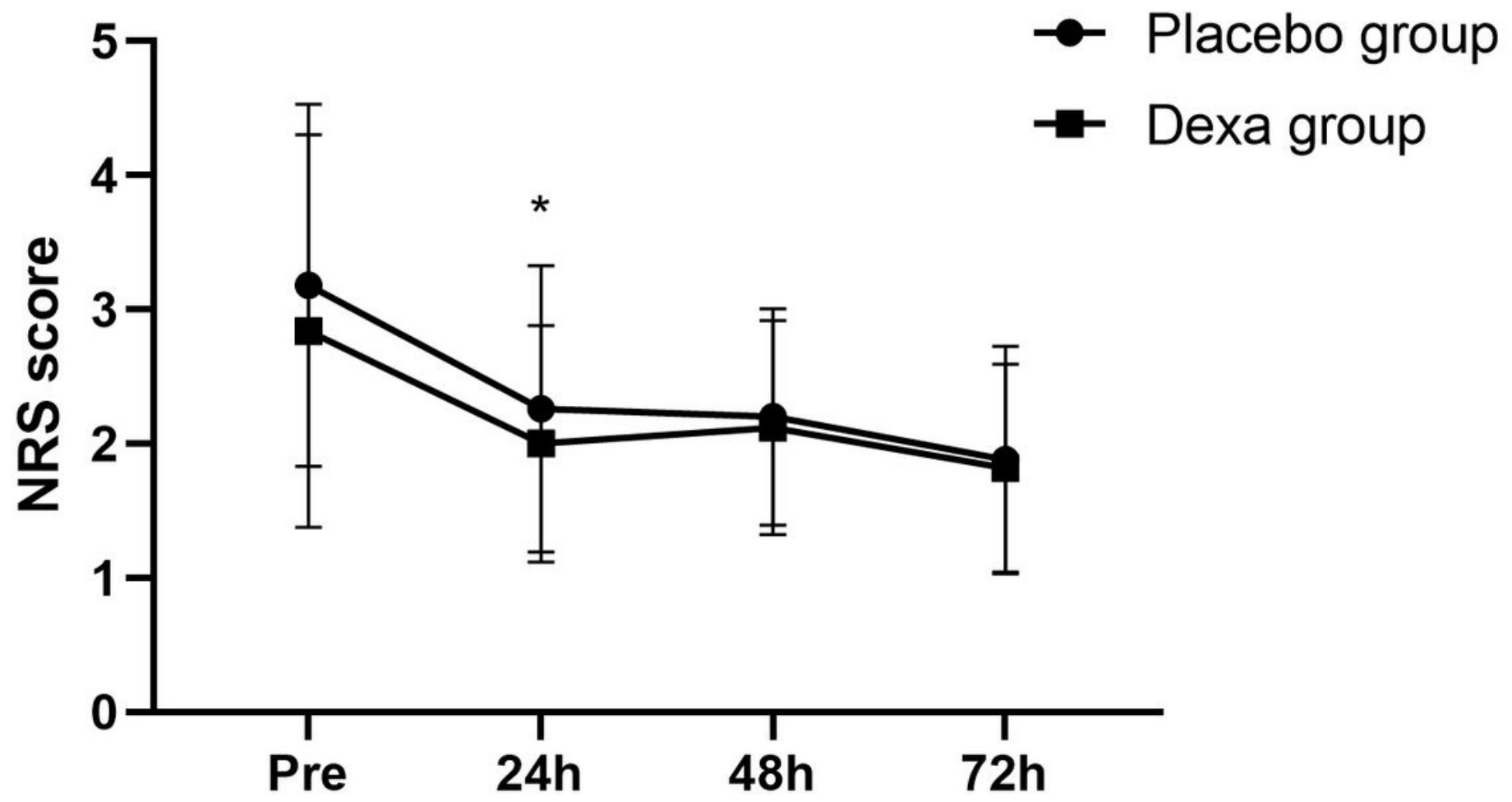

Figure 1

Pain level according to NRS score. The Wilcoxon-Mann-Whitney U-test was performed to detect the difference between the groups. ${ }^{*} \mathrm{P}<0.05$. 